\title{
María, madre y hermana de los pobres*
}

\author{
P. Álvaro Duarte**
}

\section{Resumen}

En este artículo el autor aborda la persona de María, hija de Dios Padre, madre de Dios Hijo, y esposa del Espíritu Santo desde su aspecto de madre y hermana de los pobres. el autor hace un recorrido por el Antiguo Testamento y encuentra allí indicios incipientes de una mariología que tendrá un posterior desarrollo en el Nuevo Testamento. esta opción se legitima desde el Concilio Vaticano II como un proceder adecuado para el estudio mariológico.

Palabras clave: María, madre, hermana, Sagrada escritura, Midrash.

* Duarte, Á. (2012, 19 de sep.). Conferencia. en III Congreso Internacional de Teología Mariana. Chiquinquirá, BOy: Facultad de Teología de la Universidad Santo Tomás.

** Doctor en Teología Dogmática de la Universidad Gregoriana de Roma. estudió Filosofía en el Seminario Valmaría; Teología en la Universidad Javeriana, obteniendo el título de Licenciado en Teología Dogmática. Sacerdote eudista con experiencia en el área de la docencia en teología dogmática en diversos tratados. Maestro virtual de la Red Mutis. 


\section{Prototipos marianos en el Antiguo Testamento}

La persona de María, hija de Dios Padre, madre de Dios Hijo, esposa del espíritu Santo, es el foco de nuestra atención desde el aspecto de madre y hermana de los pobres. En un vistazo a la Palabra de Dios se puede fijar la atención en el Antiguo Testamento. Si bien no se encuentra un dato mariológico propiamente dicho, existen ciertos elementos que pueden servir de indicio para un desarrollo en el Nuevo Testamento. ya el concilio Vaticano II legitima este proceder de acercamiento al texto bíblico:

La Sagrada escritura del Antiguo y del Nuevo Testamento y la venerable Tradición muestran en forma cada vez más clara el oficio de la Madre del Salvador en la economía de la salvación y, por así decirlo, lo muestran ante los ojos. Los libros del Antiguo Testamento describen la historia de la salvación, en la cual se prepara, paso a paso, el advenimiento de Cristo al mundo. estos primeros documentos, tal como son leídos en la Iglesia y son entendidos bajo la luz de una ulterior y plena revelación, cada vez con mayor claridad, iluminan la figura de la mujer Madre del Redentor. ella misma, bajo esta luz, es insinuada proféticamente en la promesa (ipsa ${ }_{l}$ sub hac luce, prophetice adumbratur in promissione) dada a nuestros primeros padres, caídos en pecado, de la victoria sobre la serpiente (cf. Gen 3, 15). Así también, ella es la Virgen que concebirá y dará a luz un Hijo, cuyo nombre será Emmanuel (/s 7, 14; coU. Mich. 5, 2-3; Mat 1, 22-23). ella misma sobresale entre los humildes y pobres del Señor, que esperan con confianza la salvación. En fin, con Ella, excelsa Hija de Sion, tras larga espera de la promesa, se cumple la plenitud de los tiempos y se inaugura una nueva economía, cuando el Hijo de Dios asumió de ella la naturaleza humana para, con los misterios de su carne, liberar al hombre del pecado (LG 55).

\section{El pobre}

en el Antiguo Testamento el tema del pobre (da/, 'aní) ocupa un lugar particular y, en cierto sentido paradójico, puesto que, si bien delante de la sociedad en general no son muy tenidos en cuenta, ante los ojos de Dios ocupan 
un lugar importante. el término "pobre" ('aní) tiene la connotación de humilde, fiel, y es muy frecuente en los salmos. Muy cercano a esta palabra está el término 'anawah, anawim que, para algunos autores, puede ser entendido como el plural de 'aní; ahora bien, el plural propio de este término es 'anayim. en el Antiguo Testamento la pobreza no aparece como un ideal sino como fruto de la injusticia, y los pobres son vistos de manera especial por parte de Dios.

Los profetas se convierten en los grandes defensores de los pobres, víctimas del comercio fraudulento (Am 8,5-6; Os 12,8), de la ambición de tierras (Miq. 2:2; Is 5,8), del abuso del poder (Am 5,7; Jer 22,13-17). Con frecuencia la actitud del pobre frente a Dios es de humildad (Sof 2,3), de temor de Dios (Prov 15,33; 22,4), de fidelidad (Ecclo 45,4). Los que tienen estas disposiciones y oran confiadamente al Señor son llamados los "pobres del Señor" ('anawim Yhoh, cfr. Sal 74,19; 149,4-5), casi a manera de una congregación de fieles humildes. En algunos lugares se mencionan grupos de "pobres": humillados, desposeídos, esclavizados, marginados (1 Sm 22,2; Juec 11,3; Sal 12). En algunos casos el grupo se identifica con todo Israel (Sal 72,2; 74,19; 147,$6 ; 149,4$; cfr. Is 49,13), o con una determinado estrato en Israel. La expresión 'aniyé 'em o 'anawé 'em se refiere con frecuencia al pueblo o a un grupo de explotados y perseguidos (Sal 9; 10; 25; 34; 37; 69; 72; 109).

Desde aquí, a manera de prototipos de María pobre, se pueden considerar algunos textos veterotestamentarios:

\section{Prototipos de María madre y hermana de los pobres}

Saldrá una rama del tronco de Jesé [y] un retoño brotará de sus raíces. Sobre él reposará el espíritu del Señor: espíritu de sabiduría y de inteligencia, espíritu de consejo [y] de fortaleza, espíritu de ciencia [y] de temor del Señor $[-y]$ lo inspirará el temor del Señor. Él no juzgará según las apariencias ni decidirá por lo que oiga decir: juzgará con justicia a los débiles [y] decidirá con rectitud para los pobres del país; herirá al violento con la vara de su boca y con el soplo de sus labios hará morir al malvado. La justicia ceñirá su cintura y la fidelidad ceñirá sus caderas (Is 11,1-5). 
La mención del "retoño de un tronco" de donde vendrá el ungido (Mesías) por el espíritu de Dios así como la presentación del ungido humilde y bondadoso, es una referencia al "tronco", al árbol cortado, figura que trae ciertamente connotaciones de humildad y que, en alguna forma llevan a pensar en María.

el tema del oráculo de la "almah" (Is 7,14) que será citado más adelante, habla igualmente de la virginidad, realidad que, en el contexto de una cultura que exalta la maternidad, resulta de una gran pobreza para la mujer.

La profecía de Miqueas resalta la pequeñez de Belén, lugar en donde María va a dar a luz a su hijo, ofrece igualmente un contexto humilde y pobre: “[y] tú, Belén efratá, la más pequeña entre las ciudades de Judá, de ti me nacerá el que debe gobernar a Israel: sus orígenes se remontan al pasado, a un tiempo inmemorial"' (Miq 5,2).

Sara, la mujer de Abraham es avanzada en edad y sin hijos. Frente a la maternidad se siente desdichada y desamparada: “¿Tendré un hijo a esta edad avanzada y siendo viejo mi esposo?" (Gén 18,12), palabra que recuerda la situación de María ante el anuncio del ángel: “¿Cómo será esto, puesto que no conozco varón?" (Lc 1,34).

es dramático también el caso de Ana, que como Sara, se siente desconsolada por no tener hijos:

Entonces Ana oró, diciendo: Mi corazón se regocija por el Señor, mi poder se exalta por Dios; mi boca se ríe de mis enemigos, porque gozo con tu salvación. No hay santo como el Señor, no hay roca como nuestro Dios. No multipliquéis discursos altivos, no echéis por la boca arrogancias, porque el Señor es un Dios que sabe; él es quien pesa las acciones. Se rompen los arcos de los valientes, mientras los cobardes se ciñen de valor; 1os hartos se contratan por el pan, mientras los hambrientos engordan; la mujer estéril da a luz siete hijos, mientras la madre de muchos queda baldía. el Señor da la muerte y la vida, hunde en el abismo y levanta; da la pobreza y la riqueza, humilla y enaltece. Él levanta del polvo al desvalido, alza de la basura al pobre, para hacer que se siente entre príncipes y que herede un trono de gloria; pues del Señor son los pilares de la tierra, y sobre ellos afianzó el orbe. Él guarda los pasos de sus amigos, mientras los malvados perecen en las tinieblas, porque el hombre no triunfa por su fuerza. eI Señor desbarata a 
sus contrarios, el Altísimo truena desde el cielo, el Señor juzga hasta el confín de la tierra. Él da fuerza a su Rey, exalta el poder de su Ungido (1 Sa 2,1-10).

San Lucas tiene en su mente la oración de Ana al escribir el Magnificat, puesto que la figura de Ana, mujer llena de fe, de humildad y de confianza en Dios, aparece como alguien muy pobre según su contexto cultural porque no tiene hijos. Es claro que el cántico de Ana sirvió de base a san Lucas para el cántico del Magnificat.

También se encuentra el caso de Judit, quien es una mujer viuda, y como tal, pobre e indefensa, pero toma conciencia de una misión muy importante frente al pueblo, la derrota del poderoso y el triunfo de los humildes y desvalidos:

Tú has hecho el pasado, el presente [y] el porvenir; Tú decides los acontecimientos presentes [y] futuros, [y] solo [se] realiza lo que Tú [has] dispuesto. Las [cosas] que Tú has ordenado se presentan [y] exclaman: “iAquí estamos!”. Porque Tú preparas todos tus caminos, [y] tus juicios están previstos de antemano. Mira que los asirios, colmados de poderío, se glorían de sus caballos [y] sus jinetes, [se] enorgullecen del vigor de sus soldados, confían en sus escudos [y] sus lanzas, en sus arcos [y] sus ondas, [y] no reconocen que Tú eres el Señor, el que pone fin [a] las guerras. ¡Tu Nombre es Señor! Quebranta [-] su fuerza con tu poder, aplasta su poderío con tu ira, porque [se] han propuesto profanar tu Santuario, manchar la Morada donde habita la Gloria de tu Nombre, [y] derribar tu altar [a] golpes de hierro. Mira su arrogancia, descarga tu indignación sobre [sus] cabezas: concédeme, aunque no soy más que una viuda, la fuerza para cumplir mi cometido. Por medio de mis palabras seductoras castiga al esclavo junto con su jefe [y] al jefe junto con [su] esclavo. ¡Abate [su] soberbia por la mano de una mujer! Porque tu fuerza no [está] en el número ni tu dominio en los fuertes, sino que Tú eres el Dios de los humildes, el defensor de los desvalidos, el apoyo de los débiles, el refugio de los abandonados [y] el salvador de los desesperados. ¡Sí, Dios de mi padre [y] Dios de la herencia de Israel, Soberano del cielo y de la tierra, Creador de las aguas [y] rey de toda la creación: escucha mi plegaria! que mi palabra 
seductora se convierta en herida mortal para los que han maquinado un plan siniestro contra tu Alianza [y] tu Santa Morada, la cumbre de Sion [y] la Casa que es posesión de tus hijos. ¡Que toda tu nación [y] cada una de sus tribus reconozcan que Tú eres Dios, el Dios de toda fuerza [y] de lodo poder, [y] que no hay otro protector fuera de ti para la estirpe de Israel! (Jdt 9,5-14).

el caso de la reina ester es el de una mujer que representa a su pueblo humillado, abatido y amenazado de muerte. Con temor ella se aproxima al rey con el fin de hacer un acto de intercesión pero, por el mismo temor, cae desmayada. Una vez el rey la reanima ella insiste en su misión y, en su calidad de madre que se preocupa por el bien de sus hijos logra su cometido:

el rey tendió hacia ester el cetro de oro. ella se levantó, permaneció de pie en presencia del rey y dijo: "Si al rey le parece bien y quiere hacerme un favor, si lo juzga conveniente y está contento conmigo, haga revocar por escrito los documentos que Amán, hijo de Hamdatá, de Agag, concibió [y] escribió para eliminar [a] los judíos de todas las provincias del Rey. ¿Cómo podré resistir, al ver la desgracia que [se] abatirá sobre mi pueblo? ¿Cómo podré ser testigo de la desaparición de mi estirpe?" (est 8,4-6).

\section{Hija de Sion}

Los textos sobre la hija de Sion, si bien se refieren a Jerusalén, han recibido una impostación mariana. En el texto de Miqueas la hija de Sion se queja y gime porque le ha llegado el momento del parto, sería un prototipo de los dolores de María:

Quéjate [y] gime, hija de Sion, [como] mujer que está de parto, porque ahora saldrás de la ciudad [y] morarás en el campo [...]. Levántate y trilla, hija de Sion, porque haré tu cuerno como de hierro [y] tus uñas de bronce: desmenuzarás a muchos pueblos, [y] consagrarás al Señor su botín, [ y] sus riquezas al Señor de la tierra (Miq, 4,10-13). 
el texto de Sofonías alude al hecho de la maternidad, pues el rey de Israel se encuentra en su seno:

¡Alégrate, hija de Sion; da gritos de alegría, Israel! ¡Alégrate, hija de Jerusalén! el Señor es el Rey de Israel en ti. ¡No temas [...] Sion! en tu seno está el Señor, tu Dios, el héroe, el Salvador. Él se llamará “yahveh salva" (So 3,14-17).

\begin{tabular}{|l|l|}
\hline Sofonías 3,14-17 & Lucas 1,28-32 \\
\hline Alégrate & Alégrate \\
\hline Hija de Sion & María \\
\hline el señor es el rey de Israel en ti & en ti permanece la gracia \\
\hline No temas Sion & No temas, María \\
\hline en tu seno está el Señor, & el Señor está contigo \\
\hline el héroe, el salvador, Rey de Israel en ti & Concebirás en tu seno y darás a luz \\
\hline Él se llamará “yahveh salva” & A quien pondrás por nombre Jesús \\
\hline
\end{tabular}

en zacarías, desde otra perspectiva, la humildad es del rey humilde, que hace humilde también a la hija de Sion: “iAlégrate sobremanera, hija de Sion; grita de júbilo, hija de Jerusalén! He aquí que viene a ti tu rey, justo [y] victorioso, humilde [...]. Proclamará la paz a las naciones" (zac 2,14; 9,9-10).

\section{San Marcos}

Aunque la perspectiva de los evangelios se centra en Jesús, sin embargo, es posible rastrear aquello que se refiere a la persona de María. San Marcos presenta la figura más antigua de María que puede rastrearse en los Evangelios. Él no habla de la infancia de Jesús sino que inicia con la presentación del Mesías (ungido), el Hijo de Dios (Mc 1,1). María aparece ya en la vida pública de Jesús. Uno de los pasajes centrales es el siguiente:

Vinieron su madre y sus hermanos y, quedándose fuera, le manda- ron llamar. Se había sentado gente a su alrededor y le dicen: "Mira, tu madre y tus hermanos te buscan allí fuera”. Él replicó: “¿quién es 
mi madre y mis hermanos?". y mirando en torno, a los que se habían sentado a su alrededor, dijo: "Aquí tienen a mi madre y mis hermanos. el que haga la voluntad de Dios, ése es mi hermano, mi hermana y mi madre" (Mc 3,31-35).

estas palabras, en alguna forma, pudieron causar cierto efecto negativo en el corazón de María; si bien representan un elogio por ser ella modelo de cumplimiento de la voluntad del Padre, a la larga es claro que hay una gran novedad con relación a la nueva familia de Jesús en la cual se superan los nexos de sangre para pasar al plano de la fe. Desde esta perspectiva, hay diversas "madres" para Jesús, aquellas que hacen la voluntad de Dios.

Hay otro texto en San Marcos que representa un puesto muy especial con relación a la persona de María:

[Se] marchó de allí [y] fue a su tierra, [y] le siguieron sus discípulos.

Cuando llegó el sábado, se puso [a] enseñar en la sinagoga, [y] los muchos que le oían se admiraban diciendo: « ¿De dónde le viene esto? ¿y qué sabiduría [es] esta que se le ha dado? ¿y tales milagros hechos por sus manos? ¿No es este el carpintero, el hijo de María [y] hermano de Santiago [y] José [y] Judas [y] Simón? ¿[y] no están sus hermanos aquí con nosotros? y se escandalizaron de él (6,1-3).

este pasaje es el inicio de una confabulación en contra de Jesús, lo cual, de igual manera es origen de preocupaciones y de dolor para la madre que sufre el rechazo que algunos dirigen a su Hijo. Este es un mérito especial del evangelio según san Marcos, pues se lleva la gloria de ser el único texto que llama a Jesús "el hijo de María", algo muy extraño en el ámbito judío de la época, donde todo hombre era nombrado a partir del nombre de su padre.

el rechazo a Jesús es uno de los grandes motivos que causan dolor y sufrimiento a María: "[Se] enteraron sus parientes [y] fueron [a] hacerse cargo de él, pues decían: 'está fuera de sí'"' (3,20-21). en este punto es claro que llaman loco a Jesús. San Marcos registra otra de las acusaciones que hacen sufrir mucho a María: "está poseído por un espíritu inmundo" $(3,22)$.

\section{San Mateo}


San Mateo aporta otros elementos para considerar la figura de María, los cuales resultan interesantes desde la perspectiva que hemos tomado. San Mateo habla de la genealogía y de la infancia de Jesús.

en cuanto a la genealogía, inicia con una presentación clara: Jesús es el Mesías (ungido), hijo de David, hijo de Abraham. Cuando la genealogía menciona a una mujer se afirma que determinado varón engendró de una mujer a susodicho, de tal forma que "Judá engendró de Tamar a Fares; David engendró de la que fue mujer de Urías a Salomón" (Gn 38,29; Sm 12,24). en el caso de María se dice solamente que "Jacob engendró a José, el esposo de María, de la cual nació Jesús" $(1,16)$. San Mateo aporta el nombre de José, el esposo de María, quien "era justo" $(1,19)$. La filiación davídica viene a través de José.

estando reunidos los fariseos le propuso Jesús esta cuestión: “¿qué piensan ustedes acerca del Mesías? ¿De quién es Hijo?" Dícenle: “De David". Replicó: “Pues ¿cómo David, movido por el espíritu le llama Señor, cuando dice: 'Dijo el Señor a mi Señor: Siéntate a mi diestra hasta que ponga a tus enemigos debajo de tus pies?"' (Sal 110,1). Si, pues David le llama Señor, cómo puede ser Hijo suyo?" (Mt 22,42-45).

María es madre del Hijo de David y del Hijo de Dios, gran misterio que le aporta tanto alegrías como sufrimientos.

\section{Virginidad de María}

Este fue el origen de Jesucristo: María, su madre, estaba comprometida con José [y], cuando todavía no habían vivido juntos, concibió un hijo por obra del Espíritu Santo. José, su esposo, que era un hombre justo [y] no quería denunciarla públicamente, resolvió abandonarla en secreto. Mientras pensaba en esto, el ángel del Señor se le apareció en sueños y le dijo:

“José, hijo de David, no temas recibir a María, tu esposa, porque lo que ha sido engendrado en ella proviene del espíritu Santo. ella dará [a] luz un hijo, [a] quien pondrás el nombre de Jesús, porque él salvará [a] su Pueblo de [todos] sus pecados". Todo esto sucedió para que 
se cumpliera lo que el Señor había anunciado por el profeta: "La Virgen [(parthenós)] concebirá [y] dará a luz un hijo [a] quien pondrán el nombre de Emanuel", [(que traducido significa)]: "Dios con nosotros", "Al despertar, José hizo lo que el ángel del Señor le había ordenado: llevó [a] María [a] su casa, [y] sin que hubieran hecho vida en común, ella dio [a] luz un hijo, [y] él le puso el nombre de Jesús (Mt 1,18-25).

Tomando en cuenta el evangelio según san Mateo, se puede considerar esta realidad inserta en el contexto bíblico. La misión fundamental de la mujer en la Biblia es la maternidad. La mujer puede estar casada (por ejemplo Sara, Ana), puede llegar a tener siete maridos, como Sara, la mujer de Tobías (Tob 3,7-10), pero si no tiene hijos su vida carece de sentido. En este sentido la virginidad constituye un factor contrario a la vocación original de la mujer, destinada a prolongar la vida (eva o Havah es la que engendra la vida): "Por eso el Señor mismo [os] dará un signo. Mirad, la virgen [(almah)] quedará encinta [y] dará [a] luz un hijo, [y] lo llamará con el nombre de emanuel" (Is 7,14).

En el "oráculo de la Almah" se encuentra esta palabra que significa "doncella", pero que en el contexto de la época tiene unas connotaciones especiales. Si una mujer queda embarazada fuera del matrimonio corre el riesgo de la lapidación, por lo que el ser "doncella" implica el ser virgen (betulah). La mujer que no puede tener hijos, consecuentemente la virgen, es considerada "pobre", es menospreciada como alguien que carga con una maldición.

En el pasaje sobre la hija de Jefté también se puede ver la existencia de otra connotación negativa de la virginidad en dicho contexto cultural:

Ella dijo [a su] padre: "que [se me] conceda esta gracia: déjame dos meses para ir [a] vagar por las montañas [y] llorar mi virginidad con mis compañeras". Él le dijo: "vete". [Y] la dejó marchar dos meses. Ella se fue con sus compañeras [y] estuvo llorando su virginidad por los montes (Jue 11,36-38).

En María la virginidad se convierte en un lugar teológico para reafirmar la iniciativa y el poder de Dios en la historia. en la genealogía de Jesús se manifiesta la debilidad de la carne: Tamar, cananea, se disfraza de meretriz para 
obtener de su suegro la descendencia de su marido difunto; Rahab, la meretriz de Jericó, engendra a Booz: Rut, la moabita, engendra a Obed, abuelo de David. Se trata de extranjeras ajenas al linaje de David, pero son ellas quiens perpetúan su linaje. La maternidad de María se realiza por la fe. Como otros nacimientos admirables en la Biblia, el nacimiento de Jesús es un milagro de Dios por la aceptación de la acción del espíritu Santo en esta creyente.

\section{San Lucas}

el inicio del evangelio según san Lucas presenta una introducción que aclara la composición de su texto:

Puesto que muchos han intentado narrar ordenadamente los hechos que han tenido lugar entre nosotros, tal como nos los han transmitido los que presenciaron personalmente desde el comienzo mismo y que fueron hechos servidores del Mensaje, también a mí, que he investigado todo diligentemente desde sus comienzos, me pareció bien escribirlos ordenadamente para ti -ilustre Teófilo-, para que conocieras la certeza de las informaciones que has recibido (Lc 1,1-4).

San Lucas se refiere a los "que presenciaron personalmente" y recoge estos testimonios en su evangelio. Se dice del evangelio según san Lucas que es el evangelio mariano. en efecto, en su evangelio encontramos datos distintos a los de los otros sinópticos. Dos veces afirma san Lucas que María es virgen (parthenos) $(1,27)$ y centra en ella la acción del Padre, del Hijo y del espíritu Santo: “envió Dios al ángel Gabriel [a] una ciudad de Galilea, llamada Nazaret, [a] una virgen desposada con un hombre llamado José, de la casa de David; el nombre de la virgen era María" (Lc 1,26-28).

La escena del nacimiento de Jesús concentra diversos elementos en la persona de María. Por especiales circunstancias, el censo ordenado por el emperador César Augusto, el niño nace en Belén, esto es, lejos de su hogar de Nazaret, lejos de su casa. San Lucas dice que "dio a luz a su hijo primogénito, lo envolvió en pañales y lo acostó en un pesebre [(fatné)]", $(2,7)$, esto es, en circunstancias de extrema pobreza: María pobre, madre del Hijo de Dios, 
hecho pobre. Vale la pena tener en cuenta que el término fatné tiene unas connotaciones especiales, de artesa.

\section{San Juan}

San Marcos registra el nombre de María una sola vez, que es memorable, al llamar a Jesús "el Hijo de María". San Mateo menciona a María cinco veces. San Lucas lo hace trece veces: doce en su evangelio y una en los Hechos de los Apóstoles. Sin embargo, San Juan no menciona el nombre de María.

"Los judíos murmuraban de él, porque había dicho: 'yo soy el pan que ha bajado del cielo'. Y decían: '¿No [es] éste Jesús, hijo de José, cuyo padre [y] madre conocemos? ¿[Cómo] puede decir ahora: He bajado del cielo?'” (Jn 6,42). Agrega san Juan en esa ocasión: “y ni siquiera sus parientes creían en él" $(7,5)$.

Solo en dos grandes ocasiones san Juan se refiere a María: en las bodas de Caná y en el Calvario. en las bodas de Caná María interviene ante una situación de necesidad. en esa ocasión los necesitados son los esposos que celebran sus bodas y María interviene con una palabra llena de contenido: "Hagan lo que él les diga" (2,5). Desde su actitud de solidaridad con el pobre actúa como una madre en dos sentidos. Como madre de Jesús, a pesar de que él le había objetado: ¿qué [nos importa] a ti y a mí, mujer? Todavía no ha llegado mi hora $(2,4)$, pero también asume una actitud maternal frente a la pareja de recién casados que "no tienen vino" $(2,3)$. Por la solidaridad de María con los necesitados, Jesús "realizó este primer signo [y] manifestó su gloria, [y] sus discípulos creyeron en él" $(2,11)$.

el otro gran momento en que san Juan hace referencia a María es en el Calvario:

Junto a la cruz de Jesús estaban su madre, la hermana de [su[ madre, María, mujer de Cleofás, [y] María Magdalena. Jesús, viendo [a su] madre [y] junto [a] ella al discípulo [a] quien amaba, dice [a su] madre: "Mujer, ahí tienes [a] tu hijo". Luego dice al discípulo: "Ahí tienes a tu madre". y desde aquella hora el discípulo la acogió en su casa $(19,25-27)$. 
La hora de Jesús y la hora de María, que en Caná no había llegado $(2,4)$, ahora se hace presente: la mujer, cuando da [a] luz, está triste porque ha llegado su hora, la del alumbramiento, pero cuando le ha nacido el niño [ya] no se acuerda del aprieto, por el gozo de que ha nacido un hombre en el mundo $(16,21)$. Es la hora dolorosa de la madre que contempla a su Hijo humillado en la cruz, y que en silencio, desde su corazón ora por su Hijo y por sus hijos adoptivos.

en el momento en que Jesús dice a su discípulo amado (cada uno de los creyentes) "Ahí tienes a tu madre", María queda constituida como madre de todos aquellos que creen, que sufren, que tienen necesidades.

\section{El Magníficat}

Virtudes de María, son las virtudes del pobre (de los anawim Yhvh): Confianza, entrega, humildad, bondad, alegría, solidaridad, silencio, oración; que en alguna forma se encuentran reflejadas en la gran oración mariana: el Magníficat. La oración está inspirada en numerosos pasajes del Antiguo Testamento: 1 Sam 2,1-11; Hab 3,18; Job 12,19-20; 5,11-12; Sal 34,2-3; 119,9; 103,1; 89,11; 107,$9 ; 34,10 ; 98,3 ; 22,9$.

El Magníficat hace eco al cántico de Ana, madre de Samuel (1 Sam 2,1-10), en el cual Dios acaba con aquellos que se creen dioses y oprimen a los demás. En los Evangelios Jesús refleja la misericordia del Padre en su preocupación por los enfermos, los pobres, los endemoniados; como la personificación de Dios tiene preferencia por los pobres, los pequeños y los oprimidos.

el Magníficat inicia de modo muy semejante al cántico que recuerda Ana: "Mi corazón se regocija por el Señor, mi poder se exalta por Dios iproclama mi alma la grandeza del señor se alegra mi espíritu en Dios, mi Salvador!" (Lc 1,46-56). en el cántico del Magníficat María asume la perspectiva misericordiosa de Dios con relación a los pobres: “Él hace proezas con su brazo: dispersa [a] los soberbios de corazón, derriba del trono [a] los poderosos [y] enaltece [a] los humildes, [a] los hambrientos los colma de bienes [y a] los ricos los despide vacíos" (Lc 1,51-53). Curiosamente, los cantos más fuertes del Antiguo Testamento son atribuidos a mujeres: María (ex 15,20-21), Judit (Jdt 16), Débora (Jue 5), Ana (1 Sam 2). el cántico recuerda las grandes 
acciones de Dios a su pueblo y el postulado de la misericordia: el amor de Dios a los pobres, a los pequeños, a los oprimidos. Así, María es esperanza para los pobres desde su amor de madre: "su misericordia llega a sus fieles de generación en generación" (Lc 1,50).

María se presenta con mucha humildad, actitud propia del pobre desde el concepto bíblico. el Señor "ha mirado la humillación de su esclava" $(1,48)$, afirma, creando una atmósfera de humildad y de misericordia que acompaña todo el cántico, con lo cual se forma un tejido en el que caben los pobres de todos los tiempos. el Magníficat presenta también una visión crítica de la realidad que tiene la sociedad que se centra en sus propios intereses idolátricos, contrastada con la perspectiva de Dios, la cual es inversa a dichos intereses.

en el texto original los verbos del cántico están en pasado (hizo proezas, dispersó, derribó, enalteció, etc.), lo cual implica una conciencia histórica de la acción salvífica de Dios. Desde el pasado María mira el presente como el cumplimiento del plan salvífico de Dios. Es el anuncio de una palabra que ha sido cumplida, lo cual genera un dinamismo profético en María que tiene como efecto en las comunidades una visión esperanzadora y positiva de la realidad. Tiene igualmente este lenguaje una fuerza teologal, pues se percibe la acción histórico-salvífica de Dios, que anuncia la victoria final de su misericordia con los más necesitados.

es el cántico que brota del corazón de María, aquilatado en la oración y en el silencio contemplativo, lo que mejor demuestra el amor inmenso hacia su Hijo. Es el canto de la madre de misericordia que toca los diversos planos de la historia. es el canto alegre de la esperanza para todos los pobres.

en el Magnificat María no se presenta como una mujer triste u oprimida, sino como una persona llena del espíritu Santo, conocedora de las realidades de los pobres, pero igualmente consciente de la urgencia de una mirada liberadora sobre la realidad. Las advertencias a los soberbios, a los poderosos y a los ricos son una invitación a que todos seamos más humanos, muy humanos; una invitación a la solidaridad de los ricos con los pobres, de los poderosos con los necesitados.

Un modelo acabado del discípulo del Señor: artífice de la ciudad celestial y eterna, pero peregrino que corre hacia la ciudad celestial y eterna; promotor de la justicia que libera al oprimido y de la caridad que 
socorre al necesitado, pero por encima de todo testigo activo del amor que edifica a Cristo en los corazones (Pablo VI, Marialis cultus, n. 37).

Totalmente dependiente de Dios y orientada por completo hacia Él por el impulso de su fe, María es, al lado de su Hijo, la imagen más perfecta de la libertad y de la liberación de la humanidad y del cosmos. es a ella a quien la Iglesia, que la tiene como madre y como modelo, tiene que dirigir sus miradas para comprender en su totalidad el sentido de su misión (Juan Pablo II, Redemptoris Mater, n. 37).

\section{Conclusión}

La consideración bíblica sobre el Magníficat en el contexto actual lleva necesariamente a pensar en la situación de Colombia y de América Latina. en los países en vías de desarrollo, cerca de un ochenta por ciento de la población la constituyen los pobres, los subempleados, los que sobreviven en la calle con el llamado "rebusque", aquellas personas cuyos ingresos son ínfimos y no pueden tener un nivel de vida decente.

La preocupación de los medios de comunicación se centra con frecuencia en sofismas de distracción: problemas de los políticos, deportes o farándula; a lo que dedican horas y horas de trasmisión, lo cual ni resuelve, ni analiza, ni se preocupa por el alto porcentaje de la población que vive en necesidad. Con frecuencia las ciencias humanas que se preocupan por las minorías se centran en análisis de pequeños grupos o subculturas con resultados que frecuentemente no desbordan los límites áulicos.

La mirada sobre minorías marginadas, sobre desplazados, sobre niños explotados o vejados ha de llevarnos a mirar a María, mujer que vivió la pobreza, que conoció el dolor pero que opta por una transformación a partir de una actitud de respeto y sencillez. Así, su presencia y su obra es una invitación a la solidaridad por parte de los poderosos hacia los pobres.

Los elementos espirituales de oración, de fe, de seguridad en el Señor son enseñanzas que aportan un valor significativo a las demás propuestas que buscan el mejoramiento de las condiciones de la mayor parte de la población. La figura de María no puede dejarnos indiferentes ante la situación 
del pobre. La palabra "no tienen vino" (o seguridad social, o vivienda, o trabajo, o familias bien constituidas), son ciertamente una invitación para encontrar una salida digna a la situación de la mayor parte de los habitantes de nuestros países.

Proclama mi alma la grandeza del Señor, [Se] alegra mi espíritu en Dios mi Salvador; porque ha mirado la humillación de su esclava. Desde ahora me felicitarán todas las generaciones, porque el poderoso ha hecho obras grandes por mí: Su nombre es santo y su misericordia llega [a] sus fieles de generación en generación. Él hace proezas con su brazo: dispersa [a] los soberbios de corazón, derriba del trono [a] los poderosos y enaltece [a] los humildes, [a] los hambrientos los colma de bienes y [a] los ricos los despide vacíos. Auxilia [a] Israel, su siervo, acordándose de su misericordia como lo había prometido a nuestros padres, [a] favor de Abraham y su descendencia por siempre (Lc 1,46$55)$.

\section{Referencias}

Marialiscultis.(1974).Disponibleen:http://www.vatican.va/holy_father/paul_vi/apo st_exhortations/documents/hf_p-vi_exh_19740202_marialis-cultus_sp.html

Redemoria Mater. (1987). Disponible en: http://www.vatican.va/holy_father/ john_paul_ii/encyclicals/documents/hf_jp-ii_enc_25031987_redemptoris -mater_sp.html 
